\title{
La presencia de la filosofía antigua en el pensamiento de Spinoza: las referencias explícitas
}

\section{The presence of ancient philosophy in the Spinoza's thought: explicit references}

\author{
Inmaculada Hoyos SÁNCHEZ
}

Centre Léon Robin

CNRS-Universidad de París IV Sorbonne -ENS de París. Francia

Recibido: 25/02/2013

Aceptado: 26/05/2013

\section{Resumen}

El objetivo general de este estudio estriba en determinar qué presencia tiene el pensamiento antiguo en la filosofía de Spinoza y qué papel desempeña en ésta. El segundo de los objetivos, más concreto, de este trabajo reside en precisar qué corriente antigua es la que mayor influencia ha tenido en la filosofía spinoziana. Y ello en lo que atañe a uno de los hilos conductores fundamentales de su pensamiento, a saber, su teoría de las pasiones. Metodológicamente se realizará un análisis de las referencias explícitas que podemos encontrar en la obra de Spinoza a autores o corrientes de pensamiento antiguas. Ello nos llevará a encontrar en el estoicismo una y, quizá la principal, de las fuentes clásicas de la teoría de las pasiones spinoziana. Y ello, especialmente, en lo que se refiere al estoicismo de Séneca.

Palabras clave: Escuelas filosóficas, ética, naturaleza humana, ontología, psicología, racionalismo.

\section{Abstract}

The aim of this paper is to determine what presence has the Ancient thought in the Spinoza's philosophy and what role performs in this one. The second aim, more spe- 
cific, consists of specifying what current of Ancient thought has had the most influence in the Spinozian philosophy. And all this, taking mainly into consideration one of the main trains of Spinoza's thought, that is, his theory of passions. The methodology consists of analyzing the explicit references that we find in the Spinoza's work to authors or currents of Ancient thought. In this respect, this paper maintains that Stoicism is one of the main sources of Spinoza's theory of passions. And specially, it is true if we think in the Seneca's Stoicism.

Keywords: Philosophical Schools, Ethics, Human Nature, Ontology, Psychology, Rationalism.

\section{Introducción}

No parece, si tenemos en cuenta el número de referencias explícitas a autores griegos y romanos que se hallan en la obra de Spinoza, que éste prestase una gran atención a la filosofía antigua. Quizá por ello la bibliografía secundaria sobre este tema es más escasa que la dedicada a otras cuestiones. Sin embargo, aunque las menciones sean escasas, y, en general, tengan un carácter crítico, atañen a temas fundamentales de la filosofía spinoziana y, de este modo, son de suma relevancia para entender el pensamiento de Spinoza con mayor detalle y profundidad'. Así pues, el objetivo general de este estudio estriba en determinar qué presencia tiene el pensamiento antiguo en la filosofía de Spinoza y qué papel desempeña en ésta. En este sentido, la idea general que orienta este estudio es aquella según la cual el pensamiento de Spinoza está más próximo a la Antigüedad greco-romana que a las filosofías de la trascendencia de carácter judeo-cristiano, que, sin embargo, Spinoza conocía mucho mejor. El segundo de los objetivos de este trabajo reside en precisar qué corriente antigua es la que mayor influencia ha tenido en la filosofía spinoziana. Y ello en lo que atañe a uno de los hilos conductores fundamentales de su pensamiento, a saber, su teoría de las pasiones.

Para lograr satisfacer ambos objetivos, la primera tarea que hay que realizar consiste en sistematizar las principales referencias directas que podemos encontrar en la obra de Spinoza a autores o corrientes de pensamiento antiguas. Ello nos llevará a encontrar en el estoicismo una y, quizá la principal, de las fuentes clásicas de la teoría de las pasiones spinoziana. Es cierto que la mayoría de las referencias de Spinoza a la Antigüedad tienen como objeto a la filosofía aristotélica. Sin embargo, en lo que res-

${ }^{1}$ Cf. F. Chiereghin, P-F. Moreau, G. Vokos. "Spinoza et 1'Antiquité classique”, Studia spinozana, 12, 1996, p. 11. 
pecta a la concepción filosófica de las pasiones, la influencia de la filosofía helenística, y, en concreto, del estoicismo, es mucho mayor. El propio Spinoza reconoce, en la correspondencia con Boxel, que la autoridad de Sócrates, Platón y Aristóteles no vale mucho para él si la comparamos con la autoridad de Epicuro o Lucrecio. Y especialmente en lo que se refiere a la terapia de las pasiones, las corrientes de pensamiento con las que Spinoza discute directamente son fundamentalmente el cartesianismo y el estoicismo. No hay ninguna referencia a otro filósofo de la Antigüedad que sea equiparable al comentario crítico expreso que en el prefacio del libro V de la Ética Spinoza dedica a la concepción y terapia estoicas de las pasiones. No obstante, como ya se ha señalado, el filósofo más citado por Spinoza es Aristóteles.

\section{Aristóteles: "bagatelas, especulaciones y lucubraciones"}

En cuanto a las referencias directas que podemos encontrar en la obra de Spinoza a Aristóteles, destaca, por una parte, que se refiera a él y a Platón como si se tratase de un binomio y, por otra, que distinga a ambos de otros pensadores antiguos que valora más positivamente. Y ello porque en la mayoría de las ocasiones en las que Spinoza menciona a Aristóteles, lo hace de una manera crítica. Así, por ejemplo, en las obras que corresponden al periodo cartesiano encontramos varias referencias críticas a Aristóteles y a los peripatéticos. Además de la alusión a la definición aristotélica del hombre como animal racional, no más verdadera - según Spinoza- que la definición platónica del hombre como animal bípedo sin plumas², la referencia al "fárrago de

\footnotetext{
${ }^{2}$ B. Spinoza, CM, I, cap. 1 (Geb.I, 235) (244-245). Las referencias a la obra de Spinoza llevan entre paréntesis la indicación Carl Gebhardt (Geb.), tomo y página correspondiente a la edición Spinoza. Opera, Heidelberg, Carl Winters Universitätsverlag, 1925. A continuación, también entre paréntesis, aparece la página correspondiente a la edición castellana de las obras de Spinoza. En el caso de Cogitata metaphysica (CM) cito según la edición preparada por A. Domínguez. Madrid, Alianza Editorial, $1988,1^{\text {a }}$ ed. revisada y actualizada en "Área de conocimiento: Humanidades" 2006. En el caso de las Epistolae (Ep), cito según la edición preparada por A. Domínguez. Madrid, Alianza Editorial, 1988. En el caso de la Ethica (E), cito según la edición preparada por Vidal Peña. Madrid. Alianza Editorial, 1987, $1^{\mathrm{a}}$ reimp. en "Área de conocimiento: Humanidades" 1998, ${ }^{5}$ 2006. En el caso de Korte Verhandeling (KV) cito según la edición preparada por A. Domínguez. Madrid, Alianza Editorial, 1990. En el caso de Renati Descartes Principia Philosophiae (PP), cito según la edición preparada por A. Domínguez. Madrid, Alianza Editorial, 1988, $1^{\text {a }}$ ed. revisada y actualizada en "Área de conocimiento: Humanidades" 2006. En el caso del Tractatus de Intellectus Emendatione (TIE), cito según la edición preparada por A. Domínguez. Madrid, Alianza Editorial, 1988, $1^{\text {a }}$ ed. revisada y actualizada en "Área de conocimiento: Humanidades" 2006. En el caso del Tractatus theologicopoliticus (TTP) cito según la edición preparada por A. Domínguez. Madrid, Alianza Editorial, 1986, $1^{a}$ ed. en "Área de conocimiento: Humanidades" 2003. En el caso del Tractatus Politicus (TP), cito también la edición preparada por A. Domínguez. Madrid, Alianza Editorial, 1986, 1ed. en “Área de conocimiento: Humanidades” 2004.
} 
distinciones de los peripatéticos" cuando se trata de definir a Dios ${ }^{3}$, y una breve mención de la célebre materia de los peripatéticos ${ }^{4}$, las alusiones explícitas más importantes que encontramos en Cogitata metaphysica [CM] tienen que ver con el concepto de vida y la concepción del alma aristotélicos; y en segundo lugar, con la confusión de la voluntad con el apetito que tiene lugar en la filosofía aristotélica.

En cuanto a lo primero, encontramos en el capítulo 6 de la segunda parte de CM una de las referencias más completas y más reveladoras del conocimiento que Spinoza tenía de Aristóteles. Y ello porque en ese texto Spinoza cita dos obras del Estagirita. En ese capítulo Spinoza se pregunta por el significado que los filósofos han dado al término vida cuando lo refieren a Dios.

"Examinaremos, - escribe- en primer lugar, la opinión de los peripatéticos. Éstos entienden por vida la persistencia del alma (anima) nutritiva mediante el calor (véase Aristóteles, De respiratione, cap. 8). Y como imaginaron tres almas (anima), a saber, la vegetativa, la sensitiva y la intelectiva, que solamente atribuyen a las plantas, a los brutos y a los hombres, se sigue que, como ellos mismos confiesan, las demás cosas carecen de vida. Mas no por eso se atrevían a afirmar que las mentes (mens) y Dios careciesen de vida. Quizá temían caer en lo contrario a la vida, es decir, que si éstos carecían de vida, hubiesen muerto. De ahí que Aristóteles (Metafísica, libro 12, cap. 7) aún da otra definición de vida, que sólo se aplica a las mentes (mens), a saber: la vida es la operación del entendimiento. En este sentido atribuye vida a Dios, porque entiende y es acto puro. Nosotros, sin embargo, no nos molestaremos demasiado en refutar a éstos. Por lo que respecta a aquellas tres almas, que atribuyen a las plantas, los brutos y los hombres, ya hemos demostrado suficientemente que no son más que ficciones, cuando mostramos que en la materia no hay nada más que estructuras y operaciones mecánicas. Por lo que se refiere a la vida de Dios, no sé por qué se llama vida al acto del entendimiento, más bien que al acto de la voluntad y otros similares. Pero, como no espero de él ninguna respuesta, paso a explicar lo que prometimos, es decir, qué es la vida"s.

De este importante texto hay que destacar dos cosas. En primer lugar, a pesar de que ésta es una de las citas de Aristóteles más completas y detalladas que pueden encontrarse en la obra de Spinoza, y también una de las más relevantes para determinar qué conocimiento tiene el filósofo holandés del Estagirita, lo cierto es que, tal y como ha puesto de manifiesto F. Manzini, Spinoza no era un lector escrupuloso del corpus aristotélico, puesto que las referencias no son del todo exactas. Y esto, aunque no se debe por entero al descuido de Spinoza sino a la edición de la obra aristotélica que manejaba, tampoco se explica enteramente por ello. Spinoza no tomó la iniciativa

${ }^{3}$ CM, II, cap. 5 (Geb. I, 259) (273-274).

${ }^{4}$ CM, II, cap. 12 (Geb. I, 280) (300).

${ }^{5} \mathrm{CM}$, II, cap. 6 (Geb. I,259-260)(274). 
de corregir por sí mismo los errores, como hubiese hecho un lector meticuloso de la obra aristotélica, lo que, por otra parte, tampoco pretendió nunca ${ }^{6}$.

Por otra parte, destaca la actitud crítica, irónica, e incluso sarcástica y mordaz, que Spinoza adopta con respecto a la filosofía de Aristóteles. En primer lugar, señala que no se tomará demasiado tiempo en refutarlo, puesto que la distinción entre las tres partes del alma no es más que una ficción, ya que en la materia no hay más que estructuras y operaciones mecánicas. El cartesianismo de Spinoza es, en este punto, claro. El vínculo entre la doctrina de las tres partes del alma y la primera definición de vida que aparece en el texto no es evidente, pero parece que bajo el punto de vista de Spinoza, Aristóteles comete el error de situar siempre el principio de la vida en el alma, y por tanto, en el cuerpo, y por tanto, en la materia, mientras que la materia es inerte. Aristóteles es, pues, culpable de hilozoísmo, porque no hace una separación lo suficientemente estricta entre lo que pertenece al viviente y lo que pertenece a la mecánica. Sin embargo, Spinoza yerra aquí en su crítica, puesto que Aristóteles combate el hilozoísmo y opone al cuerpo el principio de vida que es el alma, como la forma a la materia ${ }^{7}$. Parece que Spinoza rectifica este error en la Ética. Sin embargo, en CM todavía ve la cuestión con los ojos de Descartes.

En lo que respecta a la noción de vida atribuida a Dios, Spinoza dice no entender por qué Aristóteles llama vida al acto del entendimiento más bien que al acto de la voluntad. Y ello porque la vida no es sino la esencia o potencia de Dios, esto es, la fuerza por la que persevera en el ser, y ésta se expresa como acto del entendimiento pero también como acto de la voluntad. Sin embargo, Spinoza tampoco se esfuerza demasiado en explicar las diferencias con el planteamiento aristotélico, puesto que "no espera de él ninguna respuesta".

La segunda referencia tiene por objeto la confusión indebida de la voluntad con el apetito. Para mostrar que la voluntad y el apetito son distintos, Spinoza considera los argumentos de los adversarios. El primer argumento se refiere a Aristóteles:

“...si la voluntad pudiera querer contra el último dictamen del entendimiento, si pudiera apetecer lo contrario al bien prescrito por el último dictamen, podría apetecer el mal, percibido como tal. Es así que esto último es absurdo. Luego, también lo primero. Es fácil ver por este argumento que quienes lo proponen no entienden qué es la voluntad, ya que la confunden con el apetito que tiene el alma después de haber afirmado o negado; pues así lo aprendieron de su maestro, el cual definió la voluntad como el apetito en relación al bien. Nosotros, en cambio, decimos que la voluntad es el afirmar que esto es bueno o al revés, tal como hemos explicado anteriormente con amplitud, al referirnos a la causa del error, ya que hemos demostrado que éste se debe

${ }^{6}$ Cf. F. Manzini. "Spinoza lecteur d'Aristote”, Archives de philosophie, Bulletin de bibliographie spinoziste, 23, 2001, pp. 1-5.

${ }^{7}$ Cf. F. Manzini. Spinoza: une lecture d'Aristote. Paris, PUF, 2009, p. 39. 
a que la voluntad es más amplia que el entendimiento. Si el alma, precisamente por ser libre, no afirmara que esto es bueno, no apetecería nada"8.

La pregunta que se plantea es: ¿qué es la voluntad? ¿El apetito que sucede al juicio de que algo es bueno (Aristóteles), o bien, el juicio mismo de que algo es bueno (Descartes)? Y el problema es clásico: ¿puede la voluntad querer el mal en tanto que tal? La respuesta de los adversarios consiste en decir que la voluntad sólo tiende a lo que ella reconoce como bueno, siendo falible. Esta posición corresponde al intelectualismo socrático, pero, tal y como explica F. Manzini, Spinoza la considera propia de los partidarios de Aristóteles bajo el pretexto de que éste ha definido la voluntad como el apetito en relación al bien'. La otra respuesta es la de Descartes. El bien es aquello a lo que ha tendido la voluntad porque ella es, por definición, la instancia que decide. Pero ¿cómo explicar que se produzcan errores de juicio que nos lleven a querer el mal? El riesgo es caer en el relativismo y que no podamos nunca desear el mal, puesto que lo que elegimos es siempre bueno por la sola razón de que lo elegimos. Spinoza opta en CM por Descartes en detrimento de Aristóteles. Sin embargo en otra obra, menos cartesiana que CM, Spinoza se aproxima más a Aristóteles y se aleja de Descartes.

En Korte Verhandeling [KV] Spinoza admite un deseo de lo malo. La voluntad se identifica ahora con el apetito en relación al bien, y el deseo (cupiditas) puede ser ese apetito en relación al bien (voluntas) o, en cambio, la tendencia a lo malo (voluptas). Y en esto Spinoza sigue el razonamiento aristotélico.

"Puesto que ahora tenemos claro que no tenemos ninguna voluntad para afirmar o negar, veamos ahora, -señala Spinoza- , la correcta diferencia entre la voluntad y el deseo o qué pueda ser exactamente aquello que los latinos llaman voluntas (...) Según la definición de Aristóteles, parece que el deseo es un género que comprende bajo sí dos especies, puesto que él dice que la voluntad es el apetito o atracción que se tiene bajo el aspecto del bien. Por eso me parece que él cree que el deseo o cupiditas es todas las tendencias, ya sean al bien ya sean al mal. Pero, si la tendencia sólo es al bien o si el hombre que tiene tal tendencia, la tiene bajo al aspecto del bien, la llama voluntas o buena voluntad. En cambio, si es mala, es decir, si vemos en otro una tendencia a algo que es malo, la llama voluptas o mala voluntad. De ahí que la tendencia del alma no es algo para afirmar o negar, sino tan sólo una inclinación a alcanzar algo bajo el aspecto del bien o a huir de algo bajo el aspecto del mal"10.

En el KV Spinoza se sitúa del lado de Aristóteles al someter el deseo a una cierta apariencia del bien que lo determina. Así podemos leer que "el deseo, ya consista,

${ }^{8}$ CM, II, cap. 12 (Geb. I, 278) (297-298).

${ }^{9}$ Cf. F. Manzini. Spinoza: une lecture d'Aristote, ed. cit., p. 70.

${ }^{10} \mathrm{KV}$, II, cap. 17 (Geb.I, 85) (136). 
como algunos quieren, en las ganas o apetencia de conseguir algo de que se carece, o, como quieren otros, en conservar las cosas de que ya disfrutamos, es cierto que no puede llegar a encontrarse sino bajo la apariencia del bien"" . Además, por el fragmento antes citado, Spinoza reprocha a sus adversarios no haber distinguido lo suficiente entre el deseo y la voluntad, ésta misma definida como poder de afirmar o negar, o dicho de otra manera, como instancia de juicio. Porque el deseo no es apto para juzgar, se coloca en aval de un proceso de evaluación del que sólo aplica las conclusiones. Esta concepción aleja a Spinoza de Descartes, para quien la voluntad se puede pronunciar autónomamente en un acto libre contra el intelecto, y lo acerca a Aristóteles, para quien el deseo no hace sino seguir la evaluación precedente de una cosa juzgada buena. Spinoza y Aristóteles están de acuerdo en que el intelecto no puede tener una función motriz. Y así, ésta queda atribuida al deseo. Esto ha hecho que muchos intérpretes relacionen ciertos fragmentos del KV con aquel pasaje del $D e$ anima en el que Aristóteles se interroga por los papeles respectivos del intelecto y del apetito en la puesta en movimiento del alma ${ }^{12}$.

No obstante, a pesar de que estas referencias del KV no son de carácter tan crítico, las analogías con la filosofía aristotélica son limitadas y con el tiempo van desapareciendo. Así, Spinoza no retoma la clasificación aristotélica de los tipos de deseo en la Ética. La voluptas spinoziana tiene un papel marginal en el sistema y lejos de significar la voluntad mala, sólo designa el simple placer. La voluntas, tal y como es descrita en la Ética se parece a la voluntad buena, pero se identifica con el entendimiento en el libro II $^{13}$. Lo que no puede negarse, en ningún caso, es que la cuestión de la definición de la voluntad y su relación con el deseo y el bien, es uno de los temas centrales de la discusión entre Spinoza y Aristóteles.

El resto de referencias explícitas que podemos encontrar en el KV a la filosofía aristotélica, son, sin embargo, más negativas. De este modo, hallamos una crítica a las ideas universales referida tanto a los seguidores de Platón como a los seguidores de Aristóteles ${ }^{14}$; y una crítica a la tesis aristotélica de que la admiración debe ir precedida de una conclusión formal para tener lugar ${ }^{15}$. Hay también alusiones implícitas a los peripatéticos, a los que se critica por su definición meramente negativa de la esencia de Dios ${ }^{16}$. Y también pueden trazarse ciertos vínculos indirectos con Aristóteles, como

\footnotetext{
${ }^{11} \mathrm{KV}$, II, cap. 3 (Geb. I, 58) (105).

${ }^{12}$ Cf. F. Manzini. Spinoza: une lecture..., ed. cit., p. 67; Aristóteles, De anima, III, 9-10, 432b26-433a22.

${ }^{13}$ Cf. E, II, 49, corol. (Geb. II, 131) (179). Cf. F. Manzini. Spinoza: une lecture..., ed, cit., pp.71-72.

${ }^{14}$ Cf. KV, I, cap. 6 (Geb. I, 42-43) (87-88).

${ }^{15}$ Cf. KV, II, cap. 3, nota 2 (Geb. I, 56) (103).

${ }^{16}$ Cf. KV, I, cap. 7 (Geb. I, 44) (89)
} 
aquel que retrotrae la distinción spinoziana entre la Natura naturans y la Natura naturata hasta los comentarios latinos de Averroes al corpus aristotélico ${ }^{17}$.

En conclusión, las referencias explícitas a Aristóteles en el KV son numerosas. La presencia de Aristóteles en esta obra es importante. De hecho, es una de las obras en la que más se lo cita. Pero de nuevo nos encontramos con que la mayoría de las alusiones son de carácter crítico, y no atañen a temas esenciales de la propia argumentación de Spinoza, salvo en lo que respecta a la muy discutida cuestión de la voluntad y el deseo y su relación con el bien. En este caso, Spinoza no parece situarse tan lejos de Aristóteles, aunque es cierto que ese acercamiento se limita a esta obra de juventud, y no llega hasta la Ética, donde Spinoza parece contradecir exactamente el libro XII de la Metafisica aristotélica cuando afirma que "nosotros no intentamos, queremos, apetecemos ni deseamos algo porque lo juzguemos bueno, sino que, al contrario, juzgamos que algo es bueno porque lo intentamos, queremos, apetecemos y deseamos" $"$.

En el Tractatus theologico-politicus [TTP] también encontramos varias referencias a Aristóteles. Pero todas ellas se pueden resumir en la crítica por parte de Spinoza al propósito de los medievales, en especial, de Maimónides, de introducir las especulaciones aristotélicas y platónicas en la Escritura. La referencia es de nuevo negativa. Se trata de bagatelas, especulaciones y lucubraciones. En el prefacio del TTP, Spinoza critica a los medievales porque desprecian la razón como si estuviera corrompida por naturaleza y creen, sin embargo, que están en posesión de la luz divina.

"Si poseyeran alguna luz divina, -objeta Spinoza- aparecería, al menos en su doctrina. Ahora bien, confieso que nunca se han dado por satisfechos en su admiración hacia los profundísimos misterios de la Escritura; pero no veo que hayan enseñado nada, aparte de las especulaciones de aristotélicos y platónicos, ya que, para no dar la impresión de seguir a los gentiles, adaptaron a ellas la Escritura. No satisfechos de desvariar ellos con los griegos, quisieron que también los profetas delirasen con éstos, demostrando así claramente que no ven, ni por sueños, la divinidad de la Escritura" 19 .

A ello vuelve Spinoza en el capítulo I del TTP, donde vuelve a criticar el intento de Maimónides de "arrancar de la Escritura las bagatelas aristotélicas y sus propias ficciones. A mí entender, no hay cosa más ridícula" ${ }^{20}$. Y en el mismo sentido señala en el capítulo XIII que "si indagas qué misterios creen descubrir ellos en la Escritura, no hallarás otra cosa que lucubraciones de Aristóteles o de Platón o de otro parecido, que

${ }^{17}$ Cf. M. Gueroult. Spinoza. Dieu (Ethique I), vol. I. Paris. Aubier, 1968, apéndice no 13, p.566. Véase también la nota 97 de la edición española del KV preparada por A. Domínguez, ed. cit., p. 230.

${ }^{18}$ E, III, 9,schol. (Geb. II, 148) (206).

${ }^{19}$ TTP, Praef. (Geb. III, 9) (67).

${ }^{20}$ TTP, cap. I (Geb. III, 19) ( 83). 
será más fácil a un idiota imaginarlas en sueños, que al hombre más culto descubrirlas en la Escritura"21.

Ahora bien, es cierto que esta crítica tan mordaz la dirige Spinoza principalmente no contra Aristóteles, ni contra Platón, sino contra Maimónides. En este sentido, podemos encontrar un fragmento en el que Spinoza distingue entre el propósito de éste, y de los judíos en general, y la propia filosofía de Aristóteles que, a diferencia de la de aquéllos, no necesita ampararse en la luz divina, sino sólo en la luz natural. De este modo, Aristóteles estaba en lo cierto al pensar que las opiniones verdaderas y la forma recta de vida contribuyen a la felicidad aunque los hombres las abracen por la sola razón, y no como doctrinas reveladas a Moisés como profeta ${ }^{22}$.

En lo que respecta a la Ética y al Tratado Político [TP], las referencias explícitas son inexistentes. Pero implícitamente, sí hay algunas alusiones a Aristóteles y a la escolástica. En estas menciones implícitas, observamos, sin embargo, que hay una valoración más positiva de Aristóteles en ciertas cuestiones muy concretas. De este modo, hay cierta evolución en la manera en que Spinoza contemplaba su filosofía. Así, en el libro IV de la Ética, Spinoza señala que puesto que los hombres difícilmente pueden soportar la vida en soledad, "la definición según la cual el hombre es un animal social suele complacer grandemente a la mayoría" ${ }^{23}$. En esta referencia ya no hay ironía, ni se descalifica la propuesta aristotélica, llamándola especulación, bagatela o lucubración. En este mismo sentido, en el TP señala Spinoza que "si justamente por esto, porque en el estado natural los hombres apenas pueden ser autónomos, los escolásticos quieren decir que el hombre es un animal social, no tengo nada que objetarles"24. Parece, por tanto, que al menos en lo que respecta a esta definición, Spinoza no tenía tan mal concepto de Aristóteles. Estas referencias de las obras de madurez de Spinoza contrastan, pues, con aquellas otras, mucho más críticas, de sus obras de juventud.

En este sentido, H. A. Wolfson ha puesto de manifiesto la influencia de Aristóteles en la ética de Spinoza a través de la mediación de Descartes. Lo que él mantiene es que puede afirmarse razonablemente que la discusión de Spinoza sobre el bien supremo, la sociedad humana y las virtudes, que aparece en las proposiciones 19-73 del libro IV de la Ética, está basada en la Ética Nicomáquea. Y ello no porque se descubran en estas proposiciones ciertas similitudes en términos individuales o frases, sino porque se pueden descubrir en ellas afinidades literarias definidas en la construcción de argumentos. Y así, de todos los autores a los que se refiere Wolfson, sólo de

${ }^{21}$ TTP, cap. XIII (Geb. III, 168) (301).

${ }^{22}$ Cf. TTP, cap. V (Geb. III, 80) (168).

${ }^{23}$ E, IV, 35, schol. (Geb. II, 234) (323).

${ }^{24}$ TP, cap. II, §15 (Geb. III, 281) (99). 
Maimónides y de Descartes, y, a través de ellos, Aristóteles, puede decirse que han tenido una influencia dominante en la obra de Spinoza y lo han guiado en la formación de su propia filosofía ${ }^{25}$.

Sin embargo, la tesis que aquí se mantiene es que aunque las referencias a Aristóteles sean numerosas, es más fuerte la influencia que ejerce la filosofía helenística en Spinoza en lo que atañe a uno de los hilos conductores principales de su pensamiento, a saber, su teoría de las pasiones. Spinoza discute directamente la terapia de las pasiones que propone el estoicismo en el prefacio del libro V de la Ética. Y en lo que respecta al epicureísmo, aunque las referencias sean menores en número, también son mucho más positivas. En este sentido, la correspondencia de Spinoza con Hugo Boxel supone un testimonio muy importante para entender cuál es la visión que Spinoza tenía de la Antigüedad y cuáles son, en concreto, las fuentes clásicas de su filosofía. Y ello porque allí Spinoza hace una distinción fundamental entre Platón, Aristóteles y Sócrates, por una parte; y Epicuro, Demócrito, Lucrecio y los atomistas, por otra.

\section{La autoridad de Epicuro, Lucrecio y Demócrito: correspondencia con Hugo Boxel}

Todo comienza con el empeño de H. Boxel en recurrir a los antiguos para apoyar su propia creencia en la existencia de los espectros. "Todos los filósofos -arguye Boxel- tanto antiguos como modernos, creen estar convencidos de la existencia de los espíritus. Plutarco es testigo de ello en los tratados sobre las opiniones de los filósofos y sobre el genio de Sócrates; lo atestiguan también todos los estoicos, pitagóricos, platónicos, peripatéticos, Empédocles, Máximo de Tiro, Apuleyo y otros" ${ }^{\text {26 }}$. La respuesta de Spinoza es la siguiente:

"La autoridad de Platón, de Aristóteles y de Sócrates no vale mucho para mí. Me hubiera admirado que usted hubiera aducido a Epicuro, Demócrito, Lucrecio o a algunos de los atomistas y defensores de los átomos. Pues no es de extrañar que aquellos que han inventado las cualidades ocultas, las especies intencionales, las formas sustanciales y otras mil tonterías, hayan excogitado los espectros y duendes y que hayan creído a las viejezuelas, con lo que aumentaron la autoridad de Demócrito, cuya

${ }^{25}$ Cf. H. A. Wolfson. The Philosophy of Spinoza. Unfolding the Latent Processes of His Reasoning. Cambridge, Harvard University Press, 1962, reprint. 2 vol. in one, pp. 16-17. Hay otros autores que han puesto de manifiesto la influencia de Aristóteles en la filosofía de Spinoza. Además de los trabajos ya citados, véase O. Hamelin. "Sur une des origines du spinozisme", L'année philosophique, 11, 1900, pp. 15-28 y F. Chiereghin. "La presenza di Aristotele nel Breve Trattato di Spinoza", Verifiche. Rivista Trimestale di scienze umane, 16, 1987, pp. 325-341.

${ }^{26}$ Ep. 55 (Geb. IV, 258) (326). 
buena fama envidiaron tanto que llegaron a quemar todos los libros que él había editado con tanto encomio" ${ }^{27}$.

De esta respuesta de Spinoza hay que destacar una serie de cosas. En primer lugar, tenemos, de nuevo, una referencia crítica a Aristóteles. Las expresiones especies intencionales (teoría del conocimiento) y formas sustanciales (teoría cosmológica, hilemorfismo) son expresiones escolásticas de inspiración platónico-aristotélica. Cualidades ocultas es más bien una crítica mecanicista a la teoría formalista de Aristóteles. En las cartas 3 y 13, Spinoza se refiere de nuevo a ellas para considerarlas un asilo de la ignorancia. Y ello porque los principios de la mecánica pueden explicar las formas y cualidades de las cosas sin necesidad de recurrir a las cualidades ocultas y las formas sustanciales. Los efectos de la naturaleza, según mantiene Spinoza, resultan del movimiento, la figura, la estructura y sus diversas combinaciones ${ }^{28}$.

También Platón, junto con Sócrates, está entre aquellos cuya autoridad no vale demasiado para Spinoza. Contra Platón parece estar escrito el capítulo I del TP. Allí Spinoza critica el idealismo político de los filósofos que han olvidado la naturaleza real, transida de pasiones, de los hombres. Asimismo, a Platón se lo menciona en algunas de las críticas que Spinoza le hace a Aristóteles y que se han citado anteriormente.

El caso de Sócrates es algo diferente. Sólo encontramos una alusión explícita más, y no precisamente a su filosofía, sino a su persona. "Nosotros - escribe Spinoza- solemos realizar nuestras acciones de dos modos, a saber, o con pasiones o sin ellas. Con pasiones, como se ve de ordinario en los señores contra sus criados que han hecho algo mal, lo cual no sucede por lo general sin cólera. Sin pasiones, como se dice de Sócrates que, cuando se veía forzado a castigar a su siervo para corregirlo, nunca lo hizo cuando sentía que su ánimo estaba excitado contra ese siervo suyo" ${ }^{29}$. En este caso, Spinoza recurre a la figura de Sócrates para apoyar su crítica a la pasión del odio.

En contraste con la visión crítica que Spinoza tiene de Aristóteles, Platón y Sócrates, aparece su valoración del epicureísmo y el atomismo. ¿Qué es lo que Spinoza ve de positivo en Epicuro y Lucrecio que no ve en Platón, ni en Aristóteles ni en Sócrates? No sólo es que ellos no crean en los espectros, sino que, tal y como señala P-F. Moreau, hay un parentesco mayor, que tiene que ver, en primer lugar, con su insistencia común en refutar el mundo de la metamorfosis con la ayuda de argumentos y principios análogos, es decir, aquellos que sin apelar a los fines, afirman la unidad

\footnotetext{
${ }^{27}$ Ep. 56 ( Geb. IV, 261-262) (330-331).

${ }^{28}$ De todos los autores citados, tal y como indica A. Domínguez en la nota 341 de la edición española de la Correspondencia, sólo de Aristóteles tenía Spinoza una traducción latina. En cuanto a dicha edición latina, Domínguez cita la Opera, 2 t., Basilea, 1548 (Cf. nota 341 de la edición castellana de la Correspondencia preparada por A. Domínguez, ed. cit., p. 331.)

${ }^{29} \mathrm{KV}$, II, cap. 6 (Geb. I, 65) (113).
} 
absoluta del universo bajo leyes naturales constantes. El epicureísmo es una doctrina naturalista de la necesidad que se descifra en la afirmación de la constancia de las formas naturales. Esto es lo que ve Spinoza en Epicuro y Lucrecio, que le hace acercarse a ellos y valorarlos tan positivamente como para reprochar a Boxel que no los haya citado $^{30}$.

Demócrito también tiene una visión causal del mundo. Por ello también lo incluye en el grupo de aquellos cuya autoridad parece ser más respetable. No obstante, hay cierta ambigüedad en la visión que Spinoza tenía de él. Y así, de Demócrito admira su rigor científico, pero crítica su actitud burlona, como señala en su carta a Oldenburg. "Si aquel célebre burlón viviera en estos tiempos, - escribe- realmente se moriría de risa. A mí, empero, esas turbas no me incitan ni a reír ni a llorar, sino más bien a filosofar y a observar mejor la naturaleza humana. Pues no pienso que me sea lícito burlarme de la naturaleza y mucho menos quejarme de ella, cuando considero que los hombres, como los demás seres, no son más que una parte de la naturaleza y que desconozco cómo cada una de esas partes concuerda con su todo y cómo se conecta con las demás" ${ }^{\prime 31}$.

No obstante, a pesar de la innegable influencia de estos pensadores sobre Spinoza y de su valoración tan positiva, lo cierto es que Spinoza no vuelve a referirse a ellos explícitamente en ninguna de sus obras ${ }^{32}$. Habría que realizar, pues, un trabajo de reconstrucción de las referencias implícitas que pueden encontrarse en la obra de Spinoza a estos pensadores. Sin embargo, ello excede los límites de un estudio como éste, es decir, centrado meramente en las referencias explícitas. Si volvemos a éstas, encontramos argumentos para apoyar la tesis de acuerdo con la cual el estoicismo es una y quizá la principal de las fuentes antiguas de la filosofía de Spinoza. En primer lugar, las referencias explícitas que hallamos en la obra de Spinoza al estoicismo pueden ser menos numerosas que las que dedica a Aristóteles, pero tampoco encontramos

${ }^{30}$ Cf. P-F., Moreau. Spinoza. L'expérience et l'éternité, Paris, PUF, 1994, pp. 495-496. Moreau se refiere, en concreto, a la Carta a Herodoto y al libro I del De Rerum Natura. Para un estudio detallado de las relaciones entre Spinoza y Epicuro véase el volumen que Archives de Philosophie dedicó a esta cuestión. Especialmente, véanse los trabajos de P-F. Moreau. "Épicure et Spinoza: la physique", Archives de Philosophie, Cahier 3, 57, 1994, pp. 459-470; L. Bove. "Épicurisme et spinozisme: 1'étique", ed. cit., pp. 471-484; J. Lagrée. "Spinoza "athée \& épicurien", ed.cit., pp. 541-558.

${ }^{31}$ Ep.30 (Geb. IV, 166) (230-231).

${ }^{32}$ También hay otro pensador antiguo al que Spinoza valora muy positivamente, pero al que sólo hace referencia en una ocasión. En la carta que escribe a J. Jelles en febrero de 1671, Spinoza se refiere a los dignos pensamientos de Tales de Mileto, un sapientísimo hombre que mostró el nulo valor de la riqueza. Cf. Ep. 44 (Geb. IV, 228-229) (293). Otros pensadores antiguos a los que Spinoza conoce, aunque no valora tan positivamente, son Zenón y Diógenes el Cínico. Al primero Spinoza lo critica por su inexacto concepto de materia; y al segundo, por sus métodos de refutación, basados en los sentidos y no en la razón. Cf. PP, II, 6, schol. (Geb. I, 192) (200). 
en ellas la ironía y el sarcasmo que hay en éstas últimas. El estoicismo sí representa para Spinoza cierta autoridad. Está dispuesto a discutir con los estoicos y no se atreve a decir que no espera de ellos ninguna respuesta. Asimismo, las referencias a los estoicos atañen a temas fundamentales de la filosofía spinoziana. Y, al contrario de lo que ocurre con la filosofía de Epicuro, Lucrecio o Demócrito, Spinoza discute por extenso, y con cierto detalle, ciertas tesis estoicas. En este sentido, no se encuentra ninguna referencia a otros pensadores antiguos que sea comparable con el comentario crítico que Spinoza dedica a los estoicos en las primeras páginas del libro $\mathrm{V}$ de la Ética.

\section{El estoicismo en la obra de Spinoza}

Tal y como señala F. Akkerman, las investigaciones sobre los orígenes estoicos de la filosofía de Spinoza no han alcanzado grandes resultados hasta los años 70 del siglo pasado. En este sentido, llama la atención el hecho de que en la bibliografía spinozista preparada por J. Préposiet no haya un apartado para la relación entre Spinoza y los estoicos en el capítulo sobre el estudio de las fuentes ${ }^{33}$. No obstante, eso no quiere decir que la interpretación estoica de la filosofía spinoziana no se hubiese planteado. En este sentido, ya Leibniz cargó a Spinoza y Descartes con ser líderes de "la secta de los nuevos estoicos", aunque esta afirmación dice más sobre la propia inquietud ética y teológica de Leibniz, que sobre cómo Spinoza y Descartes concibieron su propia relación con el estoicismo ${ }^{34}$. En realidad, el primero en ser concreto en cuanto a la influencia del estoicismo en Spinoza fue Dilthey en el siglo pasado ${ }^{35}$. Él puso de manifiesto la presencia de fuentes estoicas en la obra de Spinoza, citando un gran número de temas a través de los cuales se puede rastrear esta influencia. Sin embargo, aunque el esfuerzo es muy meritorio por las remisiones, es débil desde el punto de vista metodológico. Akkerman señala, en este sentido, que Dilthey no hace una distinción clara entre lo que pertenece a la historia de la filosofía y lo que pertenece a la biografía de Spinoza. Desafortunadamente hay que decir que este defecto se encuentra también en las consideraciones posteriores sobre esta materia que aparecen en los trabajos de Dunin Borkowski y Wolfson, cuyo manual es, de todas formas, indispensable ${ }^{36}$. Dunin

\footnotetext{
${ }^{33}$ Cf. J. Préposiet. Bibliographie spinoziste. Paris, Belles Lettres, 1973.

${ }^{34}$ Cf. A. A. Long. "Stoicism in the Philosophical Tradition. Spinoza, Lipsius, Butler" in J. Miller and B. Inwood (eds). Hellenistic and early modern philosophy. Cambridge, Cambridge University Press, 2003, p. 9.

${ }^{35} \mathrm{Cf}$. W. Dilthey. "Conception du monde et analyse de l'Homme depuis la Renaissance et la Réforme", en Oeuvres vol. IV, Paris, Cerf, 1999, pp. 425-426.

${ }^{36}$ Cf. F. Akkerman. "La penurie de mots de Spinoza", Lire et traduire Spinoza. Travaux et documents du Groupe de recherches spinozistes. Vol. I. Paris, Presses d'1'Université de Paris-
} 
Borkowski y Wolfson dan la impresión de que Spinoza ha realizado una lectura muy entendida del estoicismo, lo que Gueroult ha criticado justamente. Sin embargo, la tesis de Gueroult de acuerdo con la cual Spinoza es un cartesiano y, como Descartes, desprecia la erudición, parece excesiva ${ }^{37}$.

En la historia de las investigaciones acerca de las fuentes estoicas de la filosofía de Spinoza, es digno de mención el trabajo aquí citado de F. Akkerman. Tanto F. Akkerman como O. Proietti han puesto de manifiesto el carácter humanista de Spinoza y han recogido una multitud de pasajes del corpus spinoziano en los que puede rastrearse la influencia de las Epistolas morales de Séneca ${ }^{38}$. Por otra parte, en los últimos años, y tal como señala A. Long, la estimación moderna de la afinidad estoica de Spinoza es un curioso historial de extremos ${ }^{39}$. Algunos tratamientos fidedignos de Spinoza omiten mención alguna al estoicismo ${ }^{40}$. Otros ven a Spinoza como una especie de deudor del estoicismo preocupado por rediseñarlo ${ }^{41}$. Y es que si el estado de los estudios sobre esta materia es tan variado es porque la investigación de las relaciones entre Spinoza y el estoicismo se encuentra con varias dificultades y a veces parece hallarse en un callejón sin salida. Así, quien intenta establecer un parentesco entre las dos doctrinas se arriesga a verse sometido a la objeción de que se trata aquí de una aproximación superficial que esconde, en realidad, una oposición más profunda. Pero, a su vez, el objetor se arriesga a otro reproche, a saber, no haber visto hasta qué punto esta oposición esconde ella misma otra suerte de parentesco más profundo todavía. Para cortar este género de discusión sin caer en la acusación de "simplismo" o de "vulgaridad", habría que tener un conocimiento igual de Spinoza y del estoicismo. Y esto, parafraseando lo que dice Spinoza acerca de todo lo excelso, es

Sorbonne, p. 22. Las obras a las que se refiere Akkerman son: Dunin- Borkowski, S., Spinoza, vol I., Münster, Aschendorf, 1933, pp. 492-508, donde se señala que Spinoza es un neo-estoico, y H. A. Wolfson. The Philosophy of Spinoza. Unfolding the Latent Processes of His Reasoning, ed. cit..

${ }^{37}$ Cf. M. Gueroult, op. cit., p. 441, nota 53. La crítica es de F. Akkerman. "La penurie...”, ed. cit, p. 22.

${ }^{38}$ O. Proietti. "Lettres à Lucilius. Une source du De Intellectus Emendatione de Spinoza" Lire et traduire Spinoza. Travaux et documents du Groupe de recherches spinozistes, vol. I. Paris, Presses d'1'Université de Paris-Sorbonne, 1989.

${ }^{39}$ A. A. Long. "Stoicism in the Philosophical Tradition...", ed. cit, p. 9.

${ }^{40}$ S. Hampshire. Spinoza. Londres, Faber and Faber, 1951; G. Lloyd. Self-Knowledge in Spinoza's Ethics. Ithaca, Cornell University Press, 1994. Ambos citados por A. Long, "Stoicism..., ed. cit., nota 9, p. 27.

${ }^{41}$ Cf. S. James. "Spinoza the Stoic", in T. Sorrell (ed.). The Rise of Modern Philosophy. The Tension between the New and Tradicional Philosophies from Machiavelli to Leibniz. Oxford, Clarendon Press, 1993, pp. 289-316. James mantiene que la Ética de Spinoza es fundamentalmente una reconstrucción del estoicismo. Y también O. Kristeller. "Stoic and Neoplatonic source of Spinoza's Ethics", History of European Ideas, 5, 1984, encuentra el determinismo de Spinoza claramente estoico. 
algo tan difícil como raro ${ }^{42}$. Si a esto le añadimos, lo que ponen de manifiesto ciertos intérpretes, esto es, que el siglo XX adolece de un desconocimiento tremendo del estoicismo, podemos comprobar lo difícil de apreciar la influencia de éste en la filosofía de Spinoza ${ }^{43}$. Algo similar señala M. C. Nussbaum. La filósofa norteamericana considera que en el campo de la ética y la filosofía de las pasiones, la filosofía helenística en general, y el estoicismo en particular, ha dejado una impronta, quizá sin igual, en nuestra cultura, que fue también la de Spinoza. ${ }^{44}$ En este sentido, como decimos, lo primero es tener presente cuáles son las referencias explícitas al estoicismo que se hallan en la obra de Spinoza.

Dichas referencias explícitas son tres. En primer lugar, encontramos en el Tractatus de Intellectus Emendatione [TIE] una crítica a la concepción estoica del alma, que tiene como trasfondo una crítica a la manera estoica de hacer filosofía y a su manera de entender la Naturaleza ${ }^{45}$. En segundo lugar, en el escolio de la proposición 20 del libro IV de la Ética Spinoza explica el suicidio de Séneca y así, critica la concepción estoica del suicidio del sabio $^{46}$. Y en tercer lugar, encontramos en el prefacio del libro V de la Ética una crítica a la tesis estoica del poder absoluto de la voluntad sobre las pasiones ${ }^{47}$. En el caso de las dos primeras referencias Spinoza parece estar pensando en Séneca. En el último caso, los intérpretes han puesto de manifiesto que parece tratarse también del estoicismo de Epicteto ${ }^{48}$.

3.1. De cómo los estoicos se equivocaron en su concepción de las pasiones: el prefacio del libro $V$ de la Ética

"Aquí trataré, como he dicho, solamente de la potencia del alma, o sea, de la razón y mostraré ante todo la magnitud y características de su imperio sobre los afectos, en orden a regirlos y reprimirlos. Ya hemos dicho más arriba que, desde luego, no tenemos un absoluto imperio sobre ellos. Sin embargo, los estoicos creyeron que los afectos dependen absolutamente de nuestra voluntad, y que podemos dominarlos completamente. Con todo, ante la voz de la experiencia, ya que no en virtud de sus principios, se vieron obligados a confesar que para reprimir y moderar los afectos se

\footnotetext{
${ }^{42}$ Cf. A. Matheron. "Le moment stoïcien de l'Étique de Spinoza", dans P.-F. Moreau (dir.). Le retour des philosophies antiques à l'âge classique. Tome I. Le stö̈cisme au XVIe et au XVIIe siècle. Paris, Bibliothèque Albin Michel Idées, 1999, p. 303.

${ }^{43}$ S. James. "Spinoza the Stoic", ed. cit., p. 291.

${ }^{44}$ M. C. Nussbaum. La terapia del deseo. Teoría y práctica en la ética helenística. Trad. M. Candel. Barcelona, Paidós, 2000, p. 23.

${ }^{45}$ Cf. TIE, $\$ 74$ (Geb. II, 28) (111).

${ }^{46}$ Cf. E, IV, 20, schol. (Geb. II, 224-225) (309).

${ }^{47}$ Cf. E, V, Praef. (Geb. II, 277-278) (383-384).

${ }^{48}$ Cf. B. Carnois. "Le désir selon les Stö̈ciens et selon Spinoza", Dialogue. Canadian Philosophical Review, Cahier 2, 19,1980, p. 260; y A. Matheron. "Le moment stoïcien de l'Étique de Spinoza", ed. cit., p. 302.
} 
requiere no poco ejercicio y aplicación, y uno de ellos se esforzó por ilustrar dicha cuestión, si mal no recuerdo, con el ejemplo de los dos perros, uno doméstico y otro de caza: el repetido ejercicio acabó por conseguir que el doméstico se habituase a cazar y el de caza dejase de perseguir liebres. Dicha opinión está muy próxima a la de Descartes"49.

La crítica de Spinoza es doble. En primer lugar, se critica, por imposible, la tesis estoica del poder absoluto que tenemos sobre las pasiones. Para Spinoza las pasiones forman parte de nuestra naturaleza de manera ineliminable. El hombre padece en la medida en que es una parte de la Naturaleza, que no puede concebirse por sí sola sin las demás partes ${ }^{50}$. Y el caso es que no podemos dejar de ser una parte de la Naturaleza $^{51}$. Necesitamos relacionarnos con otros modos para subsistir. Y en la medida en que permanecemos siempre afectados por causas exteriores, no podemos hacer desaparecer totalmente la tristeza. Ahora bien, estas necesarias relaciones con otros modos, esta condición nuestra de "ser parte", puede ser fuente de padecimiento, pero también de alegría, esto es, también puede ser origen de valor. Y de este modo, la crítica a los estoicos no sólo se basa en la imposibilidad de su estrategia de trato con las pasiones. Las pasiones no sólo no pueden ser eliminadas, sino que, al menos en el caso de las pasiones alegres, no deben serlo ${ }^{52}$.

El otro objetivo de la crítica spinoziana, tal y como aparece en el prefacio que acabamos de citar, se refiere a la cuestión de la voluntad. Los lineamentos de la noción estoica de voluntad están esbozados, según ha mostrado J-B. Gourinat, en la noción de prohairesis $^{53}$. La prohairesis, o la elección preliminar, está estrechamente relacionada con el uso de las representaciones y lo que está en nuestro poder. Y precisamente, según Epicteto, lo que está en nuestro poder es la opinión, la tendencia y el deseo $^{54}$. El estoico, en efecto, profesa un cierto intelectualismo moral. Nuestros deseos están en nuestro poder porque proceden de nuestros juicios u opiniones: juicios y opiniones que no son sino formas de asentimiento ${ }^{55}$. Según el estoicismo, tenemos la

${ }^{49}$ E, V, Praef. (Geb. II, 277-278) (383-384).

${ }^{50}$ Cf. E, IV, 2 (Geb. II, 212) (291).

51 "Es imposible -escribe Spinoza- que el hombre no sea una parte de la naturaleza, y que no pueda sufrir otros cambios que los inteligibles en virtud de su sola naturaleza, y de los cuales sea causa adecuada". E, IV, 4 (Geb. II, 212) (292).

${ }_{52}$ Véase, en este sentido, la asociación que tiene lugar en la filosofía spinoziana entre lo alegre y lo bueno por una parte; y lo triste y lo malo, por otra. "Por bien -señala Spinoza- entiendo aquí todo género de alegría y todo cuanto a ella conduce $\mathrm{y}$, principalmente lo que satisface un anhelo, cualquiera que éste sea. Por $m a l$, en cambio, todo género de tristeza, y principalmente, lo que frustra un anhelo". E, III, 39, schol. (Geb. II, 170) (236-237).

${ }^{53}$ Cf. J-B. Gourinat. Les stoïciens et l'âme. París, PUF, 1996, p. 95.

${ }^{54}$ Cf. Epicteto, Manual, 1, en Epicteto. Tabla de Cebes, disertaciones, fragmentos menores, manual, fragmentos. Trad. P. Ortiz García. Madrid, Gredos, 1995.

${ }_{55}^{5}$ Según el testimonio de Sexto Empírico la opinión es un asentimiento débil y falso (Contra los matemáticos VII 151= Stoicorum Veterum Fragmenta [SVF] I 67. Ed. Hans von Arnim. 
facultad de refutar o de dar nuestro asentimiento a la representación de los objetos. Tal es la moral provisoria que nos propone Epicteto en su Manual ${ }^{56}$. Sin embargo, Spinoza niega la existencia del libre arbitrio del hombre y se posiciona contra el "moralismo" estoico ${ }^{57}$. El libre arbitrio del hombre no es más que una pura ficción. El ser humano no tiene ningún poder de elegir los objetos de su deseo porque sus voliciones particulares están determinadas por la relación infinita de causas. "Todos nuestros esfuerzos o deseos se siguen de la necesidad de nuestra naturaleza" una importante diferencia en la terapia de las pasiones que elaboran el estoicismo y Spinoza. Mientras que el estoico aconseja conocer el objeto deseado y determinar si es conforme a nuestra naturaleza, Spinoza nos invita a conocer nuestros deseos y a profundizar en ellos, puesto que una mejor inteligencia de lo que somos nos hará comprender qué debemos desear, conforme a nuestra naturaleza propia.

En referencia a este texto de Spinoza, algunos intérpretes, como A. Long y R. Scottlaender, han señalado que Spinoza no tenía un conocimiento pormenorizado de la doctrina estoica sobre las pasiones y se centra sólo en los aspectos más rigoristas de esa doctrina ${ }^{59}$. No obstante, puede argüirse que precisamente en este prefacio Spinoza hace referencia a la evolución que tuvo lugar en el estoicismo, desde el más ortodoxo de Crisipo hasta el más matizado de Séneca o Epicteto, pasando por el trabajo importante de Posidonio. En este sentido, podría considerarse la hipótesis de acuerdo con la cual, y en razón de ciertas similitudes formales y de contenido, Spinoza pudo escribir este texto pensando en el De Ira de Séneca, cuyos tres libros representan las tres etapas del estoicismo en lo que se refiere a la concepción y terapia de las pasiones $^{60}$.

No obstante, y al margen del apoyo que puede tener esta hipótesis acerca del De Ira de Séneca como fuente del prefacio del libro V de la Ética, lo que parece menos cuestionable es, por una parte, que el estoicismo es la principal fuente de la teoría de las pasiones spinoziana. Y ello porque a pesar del carácter crítico de esta importante referencia explícita al estoicismo, no se encuentra en la obra de Spinoza ninguna referencia similar a ningún otro pensador antiguo. Spinoza no ha discutido o debatido su teoría de las pasiones con ningún otro filósofo, a excepción de Descartes, con la explicitud y la claridad con la que aquí discute con los estoicos. La atención que el estoicis-

Leipzig, Teubner, 1903-1905 (3 vol). En las referencias, la cifra romana designa el volumen; y la cifra árabe, el número del fragmento citado.

${ }^{56}$ Cf. B. Carnois. "Le désir... "ed. cit., p. 260.

${ }^{57}$ Ibid.

${ }^{58}$ E, IV, Appendix, cap. I (Geb. II, 266) (367).

${ }^{59}$ Cf. A. Long. "Stoicism ...", ed. cit., nota 14, pp. 27-28; y Cf. R. Scottlaender."Spinoza et le stoïcisme", Bulletin de l'Association des Amis de Spinoza, 12, 1986, p.8.

${ }^{60}$ Para un análisis detallado del De Ira y cómo aparecen representadas las tres etapas del estoicismo en este diálogo, véase J. Fillion-Lahille. Le De ira de Sénèque et la philosophie stöcienne des passions. Paris, Klincksieck, 1984. 
mo le merece a Spinoza, en lo que respecta a la cuestión de las pasiones, es tal que decide confrontar sus ideas con éste. Por otra parte, también parece bastante probable que la principal fuente de la teoría spinoziana de las pasiones sea el estoicismo tardío, más flexible y matizado, de pensadores como Séneca. Es cierto que, por los datos que tenemos acerca de las obras que se encontraron en la biblioteca de Spinoza, puede decirse que también conoció a Cicerón y a Diógenes Laercio ${ }^{61}$.

Sin embargo, las otras dos referencias explícitas que encontramos en la obra de Spinoza al estoicismo, a saber, la crítica a la concepción del suicidio del sabio que aparece en el escolio de la proposición 20 del libro IV de la Ética, así como la crítica a la concepción estoica del alma, tal y como ésta aparece en el TIE, se refieren, en concreto, a Séneca. Y además, encontramos numerosas menciones explícitas de Spinoza a Séneca a lo largo de la obra spinoziana. Todo ello, además de ciertas similitudes formales y de contenido, muestran que, muy probablemente, es el estoicismo de Séneca el que tuvo mayor influencia sobre la filosofía de Spinoza. También si recurrimos a la vía intermedia de Descartes, cuya obra conocía muy bien Spinoza, encontramos que el estoicismo que está presente en el filósofo francés es, no única pero sí fundamentalmente, el de Séneca ${ }^{62}$. Y

${ }^{61}$ Además, en el caso de Cicerón encontramos varias referencias explícitas en la obra spinoziana. Por una parte, Spinoza cita a Cicerón en su explicación de la definición de la ambición como deseo inmoderado de gloria. "Hasta los mejores- dice Cicerón- se guían en el más alto grado por el deseo de gloria. Incluso los filósofos hacen constar su nombre en los libros que escriben sobre el desprecio de la gloria."(E, III, affectuum definitiones XLIV, explicatio (Geb. II, 202) (277). La referencia es de las Disputaciones Tusculanas: “¿Y nuestros fílósofos? ¿No ponen sus nombres precisamente en los libros que escriben sobre el desprecio de la gloria?"(Cicerón. Disputaciones tusculanas, I, 15, 34. Trad. A. Medina González. Madrid, Gredos, 2005, p. 135. Véase, en este sentido, el comentario de P.-F. Moreau. Spinoza. L'expérience..., ed. cit., p. 389, nota 1. Por otra parte, Spinoza vuelve a Cicerón en el TP, a propósito de lo temible del poder dictatorial. "No obstante, -escribe Spinoza- el rumor del dictador, por citar las palabras de Cicerón, resultaba desagradable a las personas de bien. Y con razón, pues, como esta potestad dictatorial es exactamente la misma que la de un rey, puede transformarse no sin gran peligro para el Estado, en monárquica, aunque sólo sea por un breve tiempo"(TP, cap. X, $\S 1$ (Geb. III, 354) (235). A. Domínguez señala en la nota 303 de la edición castellana del TP, que esta referencia corresponde a las Cartas a su hermano Quinto, III, 8, 4, de la que Spinoza poseía una edición (Biografias, núm. 44, p. 218/144․ Cf. nota 303 de la edición castellana del TP preparada por A. Domínguez, ed. cit., p. 235). En cuanto a Diógenes Laercio, también es probable que Spinoza conociera la versión del estoicismo antiguo que nos proporcionó éste. R. Scottlaender señala que Spinoza puede haber tenido acceso al libro VII de Diógenes Laercio en una edición bilingüe de 1615, y, de este modo, pudo haber conocido la doctrina de Zenón y Crisipo (cf. R. Scottlaender, loc. cit., p. 5).

${ }^{62}$ Véase, en este sentido, R. Descartes. Correspondencia con Isabel de Bohemia y otras cartas. Especialmente la cartas del 4 y del 18 de agosto de 1645 De Descartes a Isabel. (AT, IV, 264265 y 272) (81 y 86). Citamos según la edición castellana preparada por M. T. Gallego Urrutia. Barcelona, Alba Editorial, 1999. También se incluye, en primer lugar, y entre paréntesis, el volumen y la página correspondiente a las Oeuvres de Descartes, editadas por Ch. Adam et P. Tannery (AT). Paris, Vrin, 1964-1976. En estas cartas Descartes analiza el De vita beata de Séneca. No obstante, hay cuestiones debatidas en la correspondencia que también están pre- 
así, se confirma, indirectamente, que Séneca es una de las figuras del estoicismo con mayor presencia en la filosofía de Spinoza.

\title{
3.2. Séneca en la obra de Spinoza: la inmortalidad del alma según el TIE
}

En las obras políticas de Spinoza, podemos encontrar algunas alusiones a Séneca. En concreto, Spinoza recurre a Las troyanas para confirmar sus propias tesis acerca del poder de las pasiones en política y de lo imposible de mantener un Estado a través de la coacción absoluta y la violencia. De este modo, en el capítulo V del TTP Spinoza parte de la idea de que ninguna sociedad puede subsistir sin autoridad y $\sin$ fuerza y, por tanto, sin leyes que moderen y controlen el ansia de placer y los impulsos desenfrenados.

\begin{abstract}
"No obstante, - advierte Spinoza- tampoco la naturaleza humana soporta ser coaccionada sin límite, y, como dice Séneca, el trágico, nadie ha contenido largo tiempo Estados de violencia, mientras que los moderados son estables. Porque, en la medida en que los hombres sólo actúan por miedo, hacen lo que rechazan de plano y no se fijan en la necesidad o utilidad de la acción a realizar, sino que sólo se cuidan de no hacerse reos de muerte o de ser castigados. Más aún, no pueden menos de alegrarse con el mal o perjuicio del que manda, aunque ello redunde en gran detrimento propio, y de desearle todos los males y de inferírselos tan pronto puedan. Por otra parte, nada pueden soportar menos los hombres que el servir a sus iguales y ser gobernados por ellos. Finalmente, nada resulta más difícil que volver a quitar a los hombres la libertad, una vez concedida" ${ }^{63}$.
\end{abstract}

Spinoza conoce, pues, Las troyanas de Séneca. Esta obra le sirve para ilustrar sus propias tesis acerca de los límites de la política con respecto a las pasiones, tanto en lo que respecta al uso que puede hacer de ellas en su favor, como al obstáculo que estas mismas pasiones pueden ocasionar para conservar un Estado. No obstante, Las troyanas no es la única obra de Séneca que conoce Spinoza. Tal y como han puesto de manifiesto F. Akkerman y O. Proietti, Spinoza conocía también las Epistolas morales a

sentes en otras obras de Descartes, tales como Las pasiones del alma, el Discurso del Método y los Principios de la filosofia, que Spinoza conocía muy bien.

${ }_{63}^{63}$ TTP., cap. V (Geb. III, 74) (159). En el capítulo XVI del TTP repite esta mención. Cf. TTP, cap. XVI (Geb. III, 194) (342). La referencia corresponde a Las troyanas: "El poder basado en la violencia nadie ha conseguido retenerlo mucho tiempo; el moderado, perdura." Séneca, Las troyanas, acto II, 258-259. Trad. J. Luque Moreno. Madrid, Gredos, 1979, p. 200. A. Domínguez señala en la nota 116 de la edición castellana del TTP que Spinoza poseía una edición de las tragedias, Tragediae Basilea (1541), aparte de dos versiones de las Epístolas morales a Lucilio en latín y en holandés. (Biografias, pp. 214-218, $103^{\circ}, 126^{\circ}, 135^{\circ}$ ). Cf. Nota 116 de la edición española del TTP preparada por A. Domínguez, ed. cit., p. 159. 
Lucilio, de las que poseía dos ediciones, una latina y otra holandesa, y cuya influencia sobre el TIE, parece algo bastante aceptado ${ }^{64}$.

Asimismo, encontramos en el TIE una crítica a la concepción estoica del alma, que va dirigida implícitamente contra Séneca. A veces, según explica Spinoza, algunas cosas que están en la imaginación están también en el entendimiento; pero si no se distingue entre imaginación y entendimiento, entre lo no distinto y lo verdadero, se produce un grave engaño. Y así:

\begin{abstract}
"Algunos estoicos, por ejemplo, oyeron por azar la palabra anima y, además, que es inmortal, pero sólo confusamente imaginaban ambas cosas. Por otra parte, imaginaban y, al mismo tiempo, entendían que los cuerpos sutilísimos penetran los demás y no son penetrados por ninguno. Como imaginaban todas estas cosas a la vez, manteniendo simultáneamente la certeza del axioma anterior, se convencían de inmediato de que el alma (mens) era aquellos cuerpos sutilísimos, de que estos cuerpos no son divisibles, etc." ${ }^{65}$.
\end{abstract}

Según señala O. Proietti todas estas afirmaciones de Spinoza en contra de "ciertos estoicos" conciernen directamente a las Epistolas morales de Séneca, y especialmente, a la epístola 57. En este sentido, la tesis de Proietti es que las Epistolas nutren el comienzo y el desarrollo del TIE ${ }^{66}$. La crítica de Spinoza se refiere, en términos generales, al modo confuso en que Séneca concibe el alma y su inmortalidad. El estoico parte de la certeza de un axioma, esto es, que "los cuerpos sutilísimos penetran los demás", y lo aplica erróneamente al alma, concebida desde este momento, como un cuerpo sutil, que, gracias precisamente a su sutileza, puede penetrar los demás cuerpos, sin ser penetrada por ellos, pudiendo escapar así a su peso. De este modo, queda explicado qué es el alma y en qué sentido es inmortal ${ }^{67}$. Ahora bien, a juicio de Spinoza estas tesis descansan sobre un engaño.

\footnotetext{
${ }^{64}$ F. Akkerman. "La penurie de mots de Spinoza", ed. cit., pp. 23-24. O. Proietti señala, en este sentido, que Las Epístolas morales están presentes en la biblioteca de Spinoza en la edición de Lipsio de 1649 y en la traducción al holandés de 1654 preparada por J. H. Glazemaker. (cf. Íd. "Lettres à Lucilius... " ", ed. cit., nota 6, p. 54).

${ }^{65}$ TIE, $\$ 74$ (Geb. II, 28) (111).

${ }^{66}$ O. Proietti, "Lettres à Lucilius...", ed.cit., pp. 48-49.

${ }^{67}$ Compárese esta descripción que hace Spinoza de la teoría estoica del alma y su inmortalidad con este fragmento de la epístola 57 de Séneca: "Al modo como la llama no puede ser ahoga$\mathrm{da}$, pues se dispersa en torno al cuerpo que la oprime; al modo como el aire, con un plano o en punta, no queda herido, ni fraccionado, sino que rodea de nuevo el cuerpo que le presionó; así también el alma que se compone de un elemento muy sutil no puede ser aprisionada, ni magullada en el interior del cuerpo, sino que gracias a su sutileza se abre camino a través de los mismos objetos que la oprimen. De igual modo que el rayo, aun después de haber invadido con sus sacudidas y fulgor un amplísimo espacio, tiene salida por un estrecho orificio; así el alma, todavía más sutil que el fuego, escapa a través de un cuerpo cualquiera." (Séneca, Epístolas morales a Lucilio, 57, 8. Introducción, traducción y notas I. Roca. Vol I.Madrid, Gredos, 1986, reimpr. 1994, p. 324).
} 


\begin{abstract}
"Ese engaño - explica Spinoza- surge de que conciben las cosas de forma demasiado abstracta, puesto que es por sí mismo evidente que lo que yo percibo en su verdadero objeto no puedo aplicarlo a otro. Ese error surge, finalmente, también de que no comprenden los primeros elementos de toda la Naturaleza; de ahí que, como proceden sin orden, y, pese a que los axiomas son verdaderos, confunden la Naturaleza con las cosas abstractas, se confunden a sí mismos y trastocan el orden de la Naturaleza. Nosotros, en cambio, si procedemos del modo menos abstracto posible y comenzamos lo antes posible por los primeros elementos, es decir, por la fuente y origen de la Naturaleza, no habremos de temer en absoluto tal engaño"68.
\end{abstract}

Así pues, los estoicos se equivocan en su doctrina por dos razones. En primer lugar, porque conciben las cosas de forma demasiado abstracta, aplicando inadecuadamente ciertos axiomas a las cosas infinitas, que no son su verdadero objeto, mezclando así confusamente elementos que son diversos. En segundo lugar, al concebir las cosas tan abstracta e indiferenciadamente, Séneca no ha comprendido bien los primeros elementos de la Naturaleza, de modo que ha pervertido su orden.

No obstante, O. Proietti observa atinadamente que, a pesar de que Spinoza rechaza incontestablemente esta concepción del alma y de su inmortalidad, es posible cierto acercamiento entre Spinoza y Séneca. Y ello porque las ideas de Séneca sobre la inmortalidad son vagas, a veces positivas, a veces negativas, $\mathrm{y}$, en cualquier caso, están marcadas por una preocupación eudemonista. Así pues, al final del libro V de la Ética, Spinoza vuelve implícitamente a Séneca cuando reconoce que incluso sin tener conciencia de que nuestra alma es eterna, le daremos prioridad a la moral y la religión y todo lo relacionado con la fortaleza en la que consiste nuestra libertad. La imagen del hombre fuerte que Séneca ha esbozado en numerosas páginas de las Epístolas morales, resurge en las últimas proposiciones de la Ética ${ }^{69}$. También encontramos un rechazo común de ciertas pasiones. Tanto en las Epístolas morales como en De vita beata se afirma que el supremo bien está situado en un lugar donde no hay espacio ni para la esperanza ni para el miedo ${ }^{70}$.Una tesis similar se halla en la Ética. De este modo, en las proposiciones finales del libro V, Spinoza insta a no temer la muerte y considerarnos dichosos si hemos podido recorrer el espacio de una vida entera con un alma sana en un cuerpo sano ${ }^{71}$. La influencia de Séneca es aquí fácilmente apreciable.

\footnotetext{
${ }^{68}$ TIE, $\$ 75$ (Geb. II, 28-29) (111-112).

${ }^{69}$ Cf. E, V, 41 (Geb. II, 306) (425). Véase, también, O. Proietti. "Lettres à Lucilius...”, ed.cit., p. 52.

${ }^{70}$ En la epístola 5 Séneca, en referencia a Hecatón, moralista del estoicismo medio, muestra que la esperanza y el miedo, indisolublemente ligados, han de ser rechazados. Cf. Séneca. Epístolas morales a Lucilio, 5, 7. ed. cit., p. 109. La condena del miedo a la muerte también es frecuente en las Epístolas. Véase, en este sentido, la epístola 30: "Para no temer nunca a la muerte, piensa siempre en ella." Epístolas morales 30, 18, ed. cit., p. p. 226.

${ }^{71}$ Cf. E, V, 39, schol. (Geb. II, 305) (423).
} 
En suma, Proietti quiere mostrar que la influencia de la filosofía de Séneca en la obra de Spinoza es clara. Y no sólo en lo que respecta a estas últimas proposiciones de la Ética, sino también, y a pesar de la crítica de Spinoza a la concepción estoica del alma, en el TIE, cuyas primeras páginas muestran el influjo de las Epistolas morales de Séneca. Es cierto que el sabio senequiano es distinto del sabio spinozista porque el primero se acoraza en la intimidad de su esencia como una fortaleza, mientras que para el segundo el bien supremo que alcanza tiene la característica de ser comunicable ${ }^{72}$. "A mi felicidad- escribe Spinoza al comienzo del TIE- pertenece contribuir a que otros muchos entiendan lo mismo que yo, a fin de que su entendimiento y su deseo concuerden totalmente con mi entendimiento y con mi deseo"73. Esta cuestión del carácter comunicable del bien y de la autosuficiencia del sabio pone de manifiesto las diferencias entre el planteamiento spinoziano y el estoico. Sin embargo, es conveniente subrayar también la afinidad que hay entre las primeras páginas del TIE y el estoicismo.

Y es que la conversión filosófica que evoca el comienzo del TIE es precisamente una conversión hacia el estoicismo ${ }^{74}$. Además de las similitudes formales, esto es, afinidades lingüísticas, en el tono, etc., hay tópicos del pensamiento de Séneca que se repiten. La esclavitud a la que nos someten los bienes externos perseguidos por el vulgo, la asidua meditación a través de la cual, al menos, ciertas pasiones pierden su veneno, la serenidad alcanzada por el conocimiento y el amor de Dios, son algunos ejemplos ${ }^{75}$. De este modo, y a pesar de que, tal y como reconoce Proietti, Spinoza puede haber recibido otras influencias, como por ejemplo, la de la moral ciceroniana, no parece azaroso afirmar que el carácter fascinante de las primeras páginas del TIE tiene mucho que ver con las Epistolas morales de Séneca ${ }^{76}$. Esta obra marca el principio del itinerario filosófico spinoziano; y Las troyanas, su ecuador y término. No obstante, estos trazos manifiestos y consistentes de estas dos obras en los escritos de Spinoza, conviven con diferencias en el contenido de ambos planteamientos. Y así, Proietti señala que el filósofo del XVII ha opuesto a la meditatio mortis senequiana la meditación sobre la vida en la que consiste la filosofía para él ${ }^{77}$. Precisamente con esta cuestión está relacionada la otra referencia crítica a Séneca que encontramos esta vez en la Ética.

${ }^{72}$ Cf. P. Sévérac. "Convenir avec soi, convenir avec autrui: Éthique stoïcienne et éthique spinoziste" Studia spinozana, 12, 1996, pp. 118-119.

${ }^{73}$ TIE, §14 (Geb. II, 8) (82).

${ }^{74}$ Cf. Séneca, Epístolas morales a Lucilio, 31 y 36. Cf. O. Proietti. "Lettres à Lucilius...", ed.cit, pp. 40- 41.

${ }^{75}$ Cf. TIE $\S \S 7,9,10,11$ (Geb. II, 6-8) (79-81).

${ }^{76}$ O. Proietti. "Lettres à Lucilius...", ed.cit, pp. 45 y 46.

${ }^{77}$ Loc. cit., p. 53. 


\subsection{El suicidio de Séneca en perspectiva spinoziana: el libro IV de la Ética}

En esta obra Spinoza menciona a Séneca para criticar la concepción estoica del suicido del sabio. En el escolio de la proposición 20 del libro IV de la Ética, Spinoza explica el propio suicido de Séneca desde premisas spinozianas y no estoicas. Y así, arguye que quien se suicida, lo hace porque ha sido vencido por causas exteriores contrarias a su naturaleza y nunca porque la naturaleza propia le dicte darse muerte.

“Así pues, - señala Spinoza- nadie deja de apetecer su utilidad, o sea, la conservación de su ser, como no sea vencido por causas exteriores y contrarias a su naturaleza. Y así, nadie tiene aversión a los alimentos, ni se da muerte, en virtud de la necesidad de su naturaleza, sino compelido por causas exteriores; ello puede suceder de muchas maneras: uno se da muerte obligado por otro, que le desvía la mano en la que lleva casualmente una espada, forzándole a dirigir el arma contra su corazón; otro, obligado por el mandato de un tirano a abrirse las venas, como Séneca, esto es, deseando evitar un mal mayor por medio de otro menor; otro, en fin, porque causas exteriores ocultas disponen su imaginación y afectan su cuerpo de tal modo que éste se reviste de una nueva naturaleza, contraria a la que antes tenía, y cuya idea no puede darse en el alma. Pero que el hombre se esfuerce, por la necesidad de su naturaleza, en no existir, o en cambiar su forma por otra, es tan imposible como que de la nada se produzca algo, según todo el mundo puede ver a poco que medite" ${ }^{\text {. }}$.

La concepción estoica del suicido es un ejemplo de la más alta independencia del sabio. El sabio estoico no necesita el mundo y ello, llevado al extremo, significa que puede renunciar por entero a él ${ }^{79}$. Las diferencias con la filosofía spinoziana son aquí claras. Spinoza señala que "servirse de las cosas y deleitarse con ellas cuanto sea posible (no hasta la saciedad, desde luego, pues eso no es deleitarse) es propio de un hombre sabio" ${ }^{\circ 0}$. La filosofía spinoziana es mucho más jovial que la estoica. El sabio spinoziano es más humano. Menos ideal que el estoico. Por otra parte, y tal y como ha puesto de manifiesto F. Akkerman, tras esta crítica a la concepción estoica del suicidio, se esconde una diferencia general en la concepción de la filosofía de Séneca y Spinoza. Éste último piensa la filosofía como una meditatio vitae, mientras que Séneca, en cierta medida, como una meditatio mortis. Akkerman señala que es posi-

\footnotetext{
${ }^{78}$ E, IV, 20, schol. (Geb. II, 224-225) (309-310).

79 "Encontrarás incluso - escribe Séneca- maestros de sabiduría que niegan que sea lícito hacer violencia a la propia vida y consideran como pecado que uno se convierta en su propio asesino: hay que aguardar, dicen, el final que la naturaleza determinó. Quien así habla no se da cuenta de que bloquea el camino hacia la libertad. Ninguna solución mejor ha encontrado la ley eterna que la de habernos otorgado una sola entrada a la vida y muchas salidas". Séneca, Epistolas morales 70, 14, ed. cit., p. 400.

${ }^{80} \mathrm{E}, \mathrm{IV}, 45$, schol. II (Geb. II, 244) (338).
} 
ble que Spinoza tuviese en mente la epístola 26 de Séneca cuando afirma, en la proposición 67 del libro IV de la Ética, que "un hombre libre en nada piensa menos que en la muerte y que su sabiduría no es una meditación de la muerte, sino de la vida" ${ }^{\not 1}$. En la cuestión del suicidio, las filosofías de Spinoza y Séneca son opuestas.

Para el sabio spinozista es imposible dejar de ser. Tal y como señala B. Carnois, en la filosofía de Spinoza existe una armonía total entre el esfuerzo por conservar el ser y el esfuerzo por realizar el ser propio, que, en el hombre, consiste en vivir según la razón. Esta armonía no se rompe en ninguna circunstancia. La armonía que puede romperse es la que tiene lugar entre los aconteceres del mundo y nuestro conatus, esto es, entre lo que sucede y nuestro esfuerzo por conservar y realizar el ser propio. Sin embargo, para Spinoza es metafísicamente imposible que el ser humano renuncie a vivir. Si alguien se da muerte, no lo hace en virtud de seguir los dictados de su propia naturaleza sino bajo la presión de las causas exteriores ${ }^{82}$. El suicidio jamás es considerado por Spinoza un acto virtuoso. Sin embargo, en el estoicismo no hay tampoco desacuerdo entre nuestro conatus inicial de autoconservación y el esfuerzo por realizar el ser propio del hombre, que también ellos conciben como el vivir de acuerdo con la razón. Pero en ciertas circunstancias la armonía entre ambos se encuentra rota, y, en ese caso, el segundo deseo, es decir, el esfuerzo por realizar el ser propio, supera al primero ${ }^{83}$. El sabio puede recurrir al suicidio cuando las circunstancias no le permiten elevarse a ese modo de existencia superior que le es impuesto por su naturaleza racional. De ahí que el suicido pueda ser en este caso un acto natural y virtuoso ${ }^{84}$. Ésta es una de las diferencias más radicales entre la ética estoica y la spinoziana. En este sentido, el

${ }^{81}$ Cf. F. Akkerman. "La penurie de mots...", ed. cit., p. 26. La oposición entre la proposición 67 del libro IV de la Ética de Spinoza y el siguiente fragmento de la epístola 26 de Séneca es llamativa: "Es una gran cosa aprender a morir. Piensas, quizá que es superfluo aprender aquello que nos ha de ser útil una sola vez: es ésta precisamente la razón que nos impulsa a meditar; hay que aprender continuamente aquella lección que no podemos saber si la hemos aprendido o no. Medita sobre la muerte. Quien esto dice, nos exhorta a que meditemos sobre la libertad. Quien aprendió a morir, se olvidó de ser esclavo" Séneca, Epístolas morales, 26, 8-10, ed. cit., pp. 209-210. También en la Epístola 61 Séneca recuerda que "hemos de aparejarnos para la muerte antes que para la vida". Epístola morales, 61, 4, ed. cit., p. 347.

82 "Ninguna cosa puede ser destruida -afirma Spinoza- sino por una causa exterior". E, III, 4 (Geb. II, 145) (202). Y en la proposición 10 señala que "una idea que excluya la existencia de nuestro cuerpo no puede darse en nuestra alma, sino que le es contraria". E, III, 10 (Geb. II, 148) (206).

${ }^{83}$ B. Carnois. "Le désir selon... “, ed. cit., p. 257.

${ }_{84}$ "Mas la vida, como sabes, -escribe Séneca- no debe conservarse por encima de todo, ya que no es un bien el vivir, sino el vivir con rectitud. En consecuencia, el sabio vivirá mientras deba, no mientras pueda. Considerará en qué lugar ha de vivir, en qué comunidad, de qué forma, cuál es su cometido. Piensa siempre en la calidad de la vida, no en su duración. Si le sobrevienen muchas contrariedades que perturban su quietud, abandona su puesto. Y esta conducta no la adopta sólo en caso de necesidad extrema, sino que tan pronto como la fortuna comienza a inspirarle recelo, examina atentamente sino es aquél el momento de terminar. Considera sin 
mismo Spinoza expresa, en el escolio de la proposición 18 del libro IV de la Ética, su profundo desacuerdo con el estoicismo en esta cuestión. Y lo hace, además, reconociendo las afinidades que también existen entre su ética y la moral estoica. La virtud, arguye Spinoza "no es otra cosa que actuar según las leyes de la propia naturaleza y puesto que todas las cosas singulares se esfuerzan por conservar su ser en virtud de las leyes de la naturaleza, se sigue de ello: primero, que el fundamento de la virtud es el esfuerzo mismo por conservar el ser propio, y la felicidad consiste en que el hombre puede conservar su ser. Se sigue también, segundo: que la virtud debe ser apetecida por sí misma, y que no debemos apetecerla por obra de otra causa más excelente o útil para nosotros que la virtud misma. Se sigue, por último, tercero: que los que se suicidan son de ánimo impotente, y están completamente derrotados por causas exteriores que repugnan a su naturaleza" ${ }^{\prime 85}$. Este fragmento muestra, a modo de conclusión, cuáles son las afinidades y divergencias entre la ética estoica y la spinoziana. Spinoza encuentra dos tesis estoicas en la raíz de su ética. La primera reside en hallar el primer fundamento de la virtud y felicidad en el conatus; y la segunda, en concederle a esta virtud y felicidad un valor en sí que debe ser apetecido por sí mismo. Pero la tercera tesis que menciona Spinoza en este fragmento va dirigida contra el estoicismo de Séneca. El suicidio es siempre un acto contranatural y jamás virtuoso.

En conclusión, las referencias textuales directas de Spinoza a Séneca nos dicen que Spinoza conocía las Epístolas morales y Las troyanas. En cuanto a la visión que Spinoza tiene del Séneca trágico es muy positiva. En este sentido, hemos visto cómo Spinoza recurre a él en sus obras políticas para ilustrar su tesis de que la coacción o el miedo no es un buen fundamento para la permanencia del Estado. En cuanto al Séneca moralista, hemos visto que su influencia en el TIE es bastante verosímil, aunque nunca tanto como para concluir que Spinoza tenía en mente esta obra cuando escribió la suya. La tesis de que Séneca es para Spinoza el interlocutor de un diálogo puede ser demasiado fuerte ${ }^{86}$. Pero hay argumentos suficientes para concluir que Spinoza ha leído esta obra y que esta lectura pudo dejar en su filosofía cierta impronta. En cuanto a la valoración del pensamiento del Séneca de las Epistolas, es más ambigua que la del Séneca trágico. Las referencias de Spinoza a Séneca, tanto en el TIE como en la Ética, son críticas. Hay también divergencias entre ambas filosofías tanto en la forma de expresarse como en el contenido. Pero estas divergencias conviven con afinidades igualmente relevantes.

importancia alguna darse la muerte o recibirla, que ésta acontezca más pronto o más tarde: no la teme como una gran pérdida. Nadie puede perder mucho cuando el agua se escurre gota a gota". Séneca, Epístolas morales 70, 4-5, ed. cit., pp. 396-397.

${ }_{85}$ E, IV, 18, schol. (Geb. II, 222) (306).

${ }^{86}$ Cf. F. Akkerman, "La penurie de mots...", ed. cit., p. 27. 
Tal y como señala Akkerman, en su conjunto, las ideas que Spinoza ha encontrado en la obra de Séneca debieron de parecerle en gran parte confusas, y su manera de deducir poco convincente, tal y como el mismo Descartes señala en la correspondencia con Isabel de Bohemia. La concepción del hombre senequiana debió de parecerle a Spinoza demasiado dualista; y su fe en la posibilidad de una vida razonable, demasiado grande ${ }^{87}$. Pero también hay coincidencias entre ambos filósofos. Akkerman señala la metafísica del sabio y del enfermo o del sabio y del no sabio, la verdadera alegría del sabio por contraposición a la falsa del ignorante, y el uso de ciertas nociones como la de conatus, amor naturalis y constitutio, tal y como aparecen en la epístola 26, como algunos ejemplos de ideas, distinciones y conceptos compartidos por ambos filósofos ${ }^{88}$.

\section{Conclusión}

Tras este breve recorrido por las referencias explícitas a la filosofía antigua que se encuentran en la obra de Spinoza, se pueden señalar, a modo de conclusión, las siguientes ideas.

En primer lugar, es cierto que Spinoza no tuvo un conocimiento pormenorizado del pensamiento antiguo, del que nunca fue un lector escrupuloso. Pero las referencias explícitas muestran que el pensamiento antiguo tuvo un papel importante en su filosofía. Y ello en un doble sentido. Por una parte, Spinoza recurre a los pensadores antiguos, aunque también a la literatura y la historia greco-romanas, para apoyar sus propias tesis y colmar, tal y como ha señalado F. Akkerman, su penuria de palabras ${ }^{89}$. En este sentido, las referencias al pensamiento antiguo desempeñan una función confirmativa en la filosofía de Spinoza. Como ejemplo, podemos pensar en la mención que en el TTP Spinoza hace de las Troyanas de Séneca para apoyar su propia idea acerca de los límites de la violencia como fundamento del Estado. También J. Lagrée

\footnotetext{
${ }^{87}$ Loc. cit., p. 24.

${ }^{88}$ Loc. cit., pp. 26-27.

${ }^{89}$ Loc. cit., p. 19. En cuanto a las referencias a la historia y literatura antiguas, hay que decir que es sobre todo la romana la que tiene mayor presencia. En este sentido, en las obras políticas de Spinoza se hallan numerosas referencias a Q. Curcio y a Tácito, de los que se citan obras como las Historias de Alejandro Magno de Q. Curcio, y los Anales y las Historias de Tácito. Además, se cita a otros historiadores romanos como Salustio, y también hay alguna referencia implícita a Tito Livio. En cuanto a la literatura, además de las referencias implícitas a Terencio que pueden rastrearse en los tratados políticos, destacan especialmente las menciones de Ovidio, o el Poeta, como lo llama Spinoza. Cf. TTP, cap. VII (Geb. III, 110) (211) y Metamorfosis, IV, 164 y ss; TP, cap. X, § 5 (Geb. III, 355) (238) y Amores, III, 7, 1; E, III, 31 , corol. (Geb. II, 164) (228-229) y Amores, II, 19, 4-5; E, IV, 17, schol. (Geb. II, 221) (304) у Metamorfosis, VII, 20.
} 
señala algo similar cuando dice que Spinoza usa estratégicamente el vocabulario antiguo, aunque Lagrée circunscribe esta tesis al vocabulario estoico, para introducir al lector de manera más dulce en la orientación racionalista de su filosofía y facilitar así el paso del discurso imaginativo religioso tradicional al discurso filosófico racional que rechaza lo sobrenatural ${ }^{90}$.

Además, junto a esta función confirmativa y estratégica, las referencias al pensamiento antiguo también tienen un papel adversativo o demarcativo, es decir, tal y como señala Lagrée, pretenden excluir las bagatelas y fantasías aristotélicas y platónicas, y, en su lugar, aproximarse a las filosofías naturalistas de Epicuro, Lucrecio o Demócrito. Así puede entenderse la importante referencia que aparece en la carta a Hugo Boxel que ha sido objeto de análisis. No obstante, las referencias al estoicismo también desempeñan esta doble función confirmativa o estratégica y adversativa o demarcativa. Y así, las tres alusiones explícitas que encontramos en la obra de Spinoza al estoicismo, permiten al filósofo holandés precisar sus propias tesis al distinguirlas de otras, que, en principio, pueden parecer similares. Parecería, pues, que Spinoza arguye al final del libro V de la Ética que el alma es inmortal en el sentido en que lo dijeron los estoicos, pero no es exactamente así. Parecería que Spinoza apoya el suicido del sabio, tal y como lo representa Séneca, pero tampoco es así. Y en último lugar, parecería que, como los estoicos, la terapia spinoziana aspira a eliminar las pasiones a través del esfuerzo de la razón, o la voluntad si pensamos en términos estoicos, pero tampoco es exactamente así. Y ello porque, tal y como se ha señalado, para Spinoza ni todas las pasiones pueden ser extirpadas, ni todas deben serlo. Además, la terapia spinoziana de las pasiones está basada en la razón, pero también en la potencia de ciertos afectos, como los alegres, sin los que tampoco la razón podría hacernos más felices, mejores y más libres.

Esta importante crítica a la concepción y terapia estoicas de las pasiones, tal y como se presenta en el prefacio del libro V de la Ética, permite también derivar una segunda tesis, en la que quisiera hacer especial énfasis, y es aquella según la cual el estoicismo es una, y quizá la principal, de las fuentes antiguas de la teoría spinoziana de las pasiones. En concreto, tras este breve estudio de las referencias explícitas al estoicismo, puede decirse, con algo más de precisión, que es el estoicismo tardío de pensadores como Séneca el que más y mejor conoció Spinoza. Es probable, como ya se ha advertido, que Spinoza conociera la versión del estoicismo antiguo proporcionada por Diógenes Laercio. Y así, ciertos tópicos del estoicismo más ortodoxo, como por ejemplo, el ideal del sabio insensible. Pero es, sobre todo, la filosofía senequiana la que ha dejado mayor huella en la obra de Spinoza. Y así, tanto las objeciones a la

${ }^{90}$ Cf. J. Lagrée. Spinoza et le débat religieux. Lectures du Traité théologico-politique. Rennes, Presses Universitaires de Rennes, 2004, p. 95. 
concepción y la terapia de las pasiones de los estoicos, así como las observaciones críticas sobre la inmortalidad del alma y el suicido del sabio, están referidas, principalmente, a Séneca. Y es que en el siglo XVII la transmisión del pensamiento de Séneca recibió un impulso fundamental a través de la traducción y edición que de sus obras preparó Justo Lipsio. Sin embargo, aunque es probable que Spinoza conociera la obra de Séneca a través de estas traducciones, hay que distinguir entre el estoicismo de Séneca, y el neo-estoicismo cristianizado de Justo Lipsio ${ }^{91}$. Y ello porque, tal y como se señalaba al inicio de este estudio, son precisamente las tesis que alejan al estoicismo del cristianismo, $y$, en general, de las filosofías de la trascendencia, las que, sin embargo, más lo aproximan a la filosofía de Spinoza. Dicho de otro modo, si hay cierto estoicismo en la filosofía de Spinoza, es otro distinto del neo-estoicismo de Justo Lipsio. Y ese estoicismo es el propio y genuino de Séneca.

\section{Referencias bibliográficas}

\section{Fuentes primarias}

Stoicorum Veterum Fragmenta. Ed. Hans von Arnim. Leipzig, Teubner, 1903-1905 (3 vol). CICERÓN. Disputaciones tusculanas. Trad. A. Medina González. Madrid, Gredos, 2005.

DESCARTES, R. Correspondencia con Isabel de Bohemia y otras cartas. Trad. M. T. Gallego Urrutia. Barcelona, Alba Editorial, 1999.

-Oeuvres de Descartes. Editadas por Ch. Adam et P. Tannery. Paris, Vrin, 1964-1976.

EPICTETO. Tabla de Cebes, disertaciones, fragmentos menores, manual, fragmentos. Trad. P. Ortiz García. Madrid, Gredos, 1995.

SÉNECA. Las troyanas. Trad. J. Luque Moreno. Madrid, Gredos, 1979.

-Epistolas morales a Lucilio. Vol. I. Trad. I. Roca. Madrid, Gredos, 1986, reimpr. 1994.

SPINOZA, B. Spinoza Opera. Herausgegeben von Carl Gebhardt. Heidelberg, Carl Winters Universitätsverlag, 1925 (4 vols.)

-Tratado teológico-político. Trad. A. Domínguez. Madrid, Alianza Editorial, 1986, $1^{\text {a }}$ edición en "Área de conocimiento: Humanidades" 2003.

-Tratado político. Trad. A. Domínguez. Madrid, Alianza Editorial, 1986, $1^{\text {a }}$ edición en "Área de conocimiento: Humanidades" 2004.

-Ética demostrada según el orden geométrico. Trad. Vidal Peña. Madrid, Alianza Editorial, 1987, 1ª reimpresión en "Área de conocimiento: Humanidades" 1998, ${ }^{5} 2006$.

- Principios de la filosofía de Descartes. Trad. A. Domínguez. Madrid, Alianza Editorial, 1988, 1ª edición revisada y actualizada en “Área de conocimiento: Humanidades” 2006.

${ }^{91}$ Como ya se ha señalado en nota anterior, en la biblioteca de Spinoza se encuentra las Epístolas morales de Séneca en la edición de Lipsio de 1649. Además, la traducción de Séneca que realiza Justo Lipsio viene preparada por otros trabajos anteriores en los que Justo Lipsio reconstruye el estoicismo a través de diversos testimonios de autores antiguos. Estos trabajos son el Manuductio ad Stoicam philosophiam y la Physiologia Stoicorum (1604 y 1610) (cf. M. Pohlenz. La Stoa: storia di un movimento spirituale. Trad. di O. De Gregorio. Milano, Bompiani, 2005, p. 983). 
-Pensamientos metafísicos. Trad. A. Domínguez. Madrid, Alianza Editorial, 1988, $1^{\text {a }}$ edición revisada y actualizada en "Área de conocimiento: Humanidades” 2006.

-Tratado de la reforma del entendimiento. Trad. A. Domínguez. Madrid, Alianza Editorial, 1988, $1^{\text {a }}$ edición revisada y actualizada en "Área de conocimiento: Humanidades" 2006.

-Correspondencia. Trad. A. Domínguez. Madrid, Alianza Editorial, 1988.

- Tratado Breve. Trad. A. Domínguez. Madrid, Alianza Editorial, 1990.

\section{Fuentes secundarias}

AKKERMAN, F. "La penurie de mots de Spinoza", Lire et traduire Spinoza. Travaux et documents du Groupe de recherches spinozistes. Vol. I. Paris, Presses d'1'Université de ParisSorbonne, pp. pp. 9-37.

BOVE, L. "Épicurisme et spinozisme: 1'étique", Archives de Philosophie, Cahier 3, 57, 1994, pp. 471-484;

CARNOIS, B. "Le désir selon les Stoïciens et selon Spinoza", Dialogue. Canadian Philosophical Review, Cahier 2, 19, 1980, pp. 255-277.

CHIEREGHIN, F. "La presenza di Aristotele nel Breve Trattato di Spinoza", Verifiche. Rivista Trimestale di scienze umane, 16, 1987, pp. 325-341.

CHIEREGHIN, F., MOREAU, P.-F., VOKOS, G. "Spinoza et 1'Antiquité classique", Studia spinozana, 12, 1996, pp. 11-12.

DILTHEY, W. "Conception du monde et analyse de 1'Homme depuis la Renaissance et la Réforme”, en Oeuvres vol. IV, Paris, Cerf, 1999.

FILLION-LAHILLE, J. Le De ira de Sénèque et la philosophie stö̈cienne des passions.

Paris, Klincksieck, 1984.

GOURINAT, J-B. Les stoïciens et l'âme. Paris, PUF, 1996.

GUEROULT, M. Spinoza. Dieu (Ethique I). Vol. I. Paris. Aubier, 1968.

HAMELIN, O., "Sur une des origines du spinozisme", L'année philosophique, 11, 1900, pp. 15-28.

HAMPSHIRE, S. Spinoza. Londres, Faber and Faber, 1951.

JAMES, S. "Spinoza the Stoic", in T. Sorrell (ed.). The Rise of Modern Philosophy. The

Tension between the New and Tradicional Philosophies from Machiavelli to Leibniz. Oxford, Clarendon Press, 1993, pp. 289-316

KRISTELLER, O. "Stoic and Neoplatonic source of Spinoza's Ethics", History of European Ideas, 5, 1984.

LAGRÉE, J. "Spinoza “athée \& épicurien” Archives de Philosophie, Cahier 3, 57, 1994, pp. 541-558.

-Spinoza et le débat religieux. Lectures du Traité théologico-politique. Rennes, Presses Universitaires de Rennes, 2004.

LLOYD, G. Self-Knowledge in Spinoza's Ethics. Ithaca, Cornell University Press, 1994.

LONG, A. A. "Stoicism in the Philosophical Tradition. Spinoza, Lipsius, Butler" in J. Miller and B. Inwood (eds). Hellenistic and early modern philosophy. Cambridge, Cambridge University Press, 2003, pp. 7-29.

MANZINI, F. "Spinoza lecteur d'Aristote", Archives de philosophie, Bulletin de bibliographie spinoziste, 23, 2001, pp. 1-5.

- Spinoza: une lecture d'Aristote. Paris, PUF, 2009.

MATHERON, A. "Le moment stoïcien de l'Étique de Spinoza”, dans P-F. Moreau (dir.). Le retour des philosophies antiques à l'âge classique. Tome I. Le stö̈cisme au XVIe et au XVIIe siècle. Paris, Bibliothèque Albin Michel Idées, 1999, pp. 302-316. 
MOREAU, P- F., Spinoza. L'expérience et l'éternité, Paris, PUF, 1994. 470

_Épicure et Spinoza: la physique", Archives de Philosophie, Cahier 3, 57, 1994, pp. 459-

NUSSBAUM, M. C. La terapia del deseo. Teoría y práctica en la ética helenística. Trad. M. Candel. Barcelona, Paidós, 2000.

POHLENZ, M. La Stoa: storia di un movimento spirituale. Trad. di O. De Gregorio. Milano, Bompiani, 2005.

PREPOSIET, J. Bibliographie spinoziste. Paris, Belles Lettres, 1973.

PROIETTI, O. "Lettres à Lucilius. Une source du De Intellectus Emendatione de Spinoza" Lire et traduire Spinoza. Travaux et documents du Groupe de recherches spinozistes, vol. I. Paris, Presses d'1'Université de Paris-Sorbonne, 1989, pp. 39-59.

SÉVÉRAC, P . "Convenir avec soi, convenir avec autrui: Éthique stoïcienne et éthique spinoziste" Studia spinozana, 12, 1996, pp.105-119

SCOTTLAENDER, R."Spinoza et le stoïcisme", Bulletin de l'Association des Amis de Spinoza, 12, 1986, pp. 1-8.

WOLFSON. H. A., The Philosophy of Spinoza. Unfolding the Latent Processes of His Reasoning. Cambridge, Harvard University Press, 1962, reprint. 2 vol. in one.

Inmaculada Hoyos Sánchez

Centre Léon Robin. CNRS-Universidad de París IV Sorbonne -ENS de París. Francia ihoyos@ugr.es 